\title{
Putting Lewin's Equation to the Test: Assessing the Person-Situation Interaction with the B5PS
}

Master's Thesis by Kai Horstmann

Humboldt Universität zu Berlin

Supervisors:

Kai Horstmann

Hornstr. 3, 10963 Berlin

horstmak@hu-berlin.de

556129

February $27^{\text {th }}, 2015$
Prof. Dr. Matthias Ziegler Humboldt Universität zu Berlin

Dr. John Rauthmann

Humboldt Universität zu Berlin 


\begin{abstract}
Lewin hypothesized in 1936 that behavior is a result of the person's personality and the environment. This basic distinction of two factors influencing behavior led to the personsituation debate. The current study briefly reviews the debate with its major arguments and concepts, putting a special focus on the newly developed concept of situation perception as a substitute for the Lewinian environment. A questionnaire is used to measure the Big Five personality dimensions as well as five dimensions of situation perception. Applying a linear multilevel model, the effects of the specific and the general situation perception and the personality on hypothetical behavior are tested. Depending on the personality and situation perception dimensions examined, it was found that the specific as well as the general situation perception have an effect on human behavior. Additional findings and promising ideas for further research are presented and discussed.
\end{abstract}


As early as 1936, Kurt Lewin proposed what is known as Lewin's Equation - Behavior is a result of both the person and the environment: $B=f(P E)$ (Lewin, 1936, p. 12). This equation can be understood as a law as well as a guideline for the proper examination and explanation of human behavior. As Lewin states "one can hope to understand the forces that govern behavior only if one includes in the representation the whole psychological situation" (Lewin, 1936, p. 12). This formal representation of the factors influencing behavior does only serve as a starting point for any psychological explanation or theory. As can be seen, no formal mathematical operator or explicit weight is incorporated in the equation. Thus, the relative importance of the person and the environment as well as their actual definitions remained unsatisfyingly unclear - as well as the empirical validity of the equation. It is among other things this imprecise definition of concepts that has fuelled a major controversy, the person-situation debate (Funder, 2009).

To further investigate Lewin's Equation, this study will briefly review this personsituation debate together with its major arguments and accurately define the relevant concepts and their substitutes that make an examination feasible. Among others, these will be the definition of the personality, the environment, their relatedness to the situation, the subjective perception of the environment as well as a mechanism, which might serve as the formal operator for combining $P$ and $E$. Via a new questionnaire, the Big Five Inventory for Personality in Occupational Situations (B5PS, Big Five Inventar zur Persönlichkeit in beruflichen Situationen; Ziegler, 2014), the equation will finally be put to the test. 


\section{The Person-Situation Debate and its Relevant Concepts}

It is the shortcomings of the relevant concepts of the person-situation debate that have lead to the person-situation debate. Starting with Lewin's Equation, three concepts need clarification: The behavior, the person and the situation.

Behavior can be defined as "behavior or any kind of mental event" (Lewin, 1936, p. 11) or may further be understood as any meaningful activity a person performs in his or her daily life (Baumeister, Vohs, \& Funder, 2007). It may therefore be anything such as a thought (mental event), a decision, a movement or even a particular answer in a questionnaire.

The person may be characterized "by qualities that are relatively invariant across situations and over time" (Shoda \& Mischel, 2000, p. 407), or in other words by the stable differences of individuals (Asendorpf, 2009). Both definitions focus on the stability of characteristics and usually refer to personality traits. It is the traits' assumed stability that allows predictions and explanations of behavior (Edwards \& Templeton, 2005; Epstein, 1983). At the same time, it is the Achilles' heel in the overall concept of personality. If the assumption of stability or at least relative stability does not hold, predictions based on these characteristics are invalid and of no use. In 1968, Mischel (Personality and Assessment, 1968) focused on this lack of empirical stability as well as the traits' actual inability to predict behavior to criticize the concept of traits and thereby triggered the person-situation debate (Funder, 2009; Mischel, 2009).

The next concept that needs clarification is the situation, which is different from the Lewinian environment: For Lewin (1936), the environment is everything apart from the personality, everything external, such as a room with furniture yet not the person in it. According to Lewin, a situation describes the person in that particular environment. In the context of the person-situation debate though, a situation is complementary to the Lewinian environment, leading sometimes to reformulations of the equation as $B=f(P S)$ (e. g. Funder, 2006; Yang, Read, \& Miller, 2006). This approach separates the situation from the person in a way Lewin actually did not define it: For Lewin, the situation (S) is a product of the person in a particular environment, thus how the person perceives the environment (cf. Lewin, 1936, pp. 24-25).This subjective approach to situational taxonomies, which will be discussed later, is the foundation for the examination of the environment within the current study.

Taking this idea into account, the person and the situation were never separable and could not have led to this false dichotomy of person and situation that drove the debate (Funder, 2006). Yet for now, the person and his or her personality will be separated from the 
situation, understood as the Lewinian environment, for an individual examination. As will be seen, both should be taken into account to properly predict behavior.

\section{The Stability of Personality - Across Time, Across Situations}

The question of stability, i. e., to what degree people show comparable behavior over time, which may allow estimating the behavior-relevant trait, has received considerable attention within the person-situation debate (Fleeson \& Noftle, 2009).

It was successfully shown that at least some personality traits correlate with external criteria, such as career success (Barrick, Mount, \& Judge, 2001; Judge, Heller, \& Mount, 2002; Ones, Mount, Barrick, \& Hunter, 1994; Ozer \& Benet-Martínez, 2006; Salgado, 1997; Schmidt \& Hunter, 1998), that they are relatively stable over the life span (Roberts \& DelVecchio, 2000) and that traits can predict behavior from one point in time to another (Epstein, 1983). The overall stability might change across the lifespan (Lucas \& Donnellan, 2011) and there is also variability in the trait measures - a person behaves sometimes differently from what is expected according to his or her measured trait (Fleeson, 2004; Mischel \& Shoda, 1995; Shoda \& Mischel, 2000). A trait (or the behavior affected by the trait) is therefore not perfectly stable over time and situations (Sherman, Nave, \& Funder, 2010). This is referred to as intra-person or within-person variability.

There are two different approaches in dealing with this intra-person variability. The first is to aggregate multiple measurements in order to obtain reliable values, thus treating the within-person variability as measurement error (e. g. Epstein, 1979), even though it may actually be systematic behavior. Over a longer period of time this approach will make broad, yet rather imprecise predictions of behavior (Mischel \& Peake, 1982; Orom \& Cervone, 2009); furthermore, as Bem and Allen (1974) and Fleeson (2004) point out, a highly variable trait cannot be considered a trait. It is therefore in the researcher's interest to investigate the cause for this variability, which leads directly to the second approach. Variability is considered meaningful and not just as random measurement error. This approach is also related to the concept of consistency as described in the next paragraph (Sherman et al., 2010).

Sherman and colleagues (2010) define three concepts of consistency: Absolute consistency, rank-order consistency and ipsative consistency. The first describes behavior or personality that does not change at all or very little. Assuming that the behavior of a person is solely influenced by the trait and the trait was perfectly stable, this would lead to an invariant behavior. The person with an absolutely consistent trait would always behave the same. 
Rank-order consistency refers to stability in comparisons to other individuals: The mean level of the considered trait, say anxiousness, may change, yet the relative position of two individuals does not. Unless the environment (in a Lewinian sense) does not change dramatically and only the time changes, both types of consistencies have been shown to a certain extend; the rank-order consistency being the more relevant and more realistic one (Mischel \& Peake, 1982; Sherman et al., 2010). These first two types of consistency are also of major relevance to psychologists since they allow the broad predictions described above, such as career success or life satisfaction. If the Lewinian environment changes, though, both consistencies are significantly reduced (Mischel \& Shoda, 1995) or - in other words - the environment influences the behavior of a person. There may nevertheless be a consistent behavior; a person behaves the same across several similar environments, which is then ipsative consistency. ${ }^{1}$

For a better understanding of ipsative consistency, imagine Matt: He is very helpful and friendly most of the time, even more so than most of his colleagues. Yet, whenever he sets foot on a sports field, he turns into a very unfriendly competitor, thereby increasing his within-variability of his trait, say, for example, agreeableness. He is also less friendly then most of his colleagues now, changing his rank. Thus, he neither shows absolute consistency nor rank-order consistency. Being an unlikeable person whenever he is on a pitch, he shows ipsative consistency. As this example shows, that, if one wants to account for the withinperson variability, the environment has to be taken into account as well. Thus, "a new locus of stability is found" (Mischel, Shoda, \& Mendoza-Denton, 2002, p. 50). If, however, the environment is not taken into account, the within-person variability can only be understood as measurement error plus the influence of the current environment. It is therefore necessary to investigate the effect the current environment has on behavior. Furthermore, it needs to be examined whether this effect can be measured, is systematic and will then allow a better prediction of behavior.

\section{The Influence of the Environment on Behavior}

There is considerable agreement on the fact that the environment - or the situation influences behavior. This was shown empirically (Bem \& Allen, 1974; Deinzer et al., 1995; Fleeson, 2004; Furr \& Funder, 2004; Mischel \& Peake, 1982; Mischel, 1968; Sherman et al.,

\footnotetext{
1 Note the difference between rank-order consistency and ipsative consistency: Both are measured over different occasions; the first assumes that the effect on behavior of a situation is the same for all persons. The second does not.
} 
2010; Shoda, Mischel, \& Wright, 1994) as well as theoretically argued for (Endler \& Magnusson, 1976; Fleeson \& Noftle, 2009; Johnson, 1999; Lewin, 1936; Magnusson, 1971; Mischel \& Shoda, 1995; Mischel, 2004, 2009; Reis, 2008; van Mechelen \& De Raad, 1999; Wagerman \& Funder, 2009). Since the environment does influence behavior, it is important to further investigate its effect as well as the underlying mechanism. It is here that the distinction of situation and environment comes into play.

If the effect of a situation is to be examined and separated from measurement error, there clearly has to be a conceptualization of the situation. On the one hand, a situation can be objectively defined, as in the Lewinian environment. This was, however, not very successful (Edwards \& Templeton, 2005; Hogan, 2009; Rauthmann et al., 2014; Saucier, Bel-Bahar, \& Fernandez, 2007). One downside of this objective approach is finding an exhaustive list of elements describing a situation or naming the features of a situation that are actually relevant for the prediction of behavior. Furr and Funder (2004), however, point out that the influence of (at least) particular aspects of a situation may be examined by comparing behavior in two objectively comparable situations that differ only in the relevant aspect.

On the other hand, situations may be defined as what the person perceives to be relevant within a certain environment. In a Lewinian sense, the situation equals the person and the environment: $S=P E$ (Lewin, 1936, p. 12). In more recent articles, this is described as the situation perception or the subjective approach as opposed to the objective approach described above (e. g. Furr \& Funder, 2004). The subjective approach combines two aspects: First, even across different people, there is overlap in the perception of relevant features of the same situation (Asendorpf, 2009; Funder, 2006; Wagerman \& Funder, 2009). For example, most people will perceive a party as more lively than a funeral. Secondly, there may be a tendency of a person to perceive different situations in a similar way; a tendency of a person that lies within that person and thus exerts its effect on behavior across different situations (Sherman et al., 2010). The subjective approach has received support from various researchers (Bem \& Allen, 1974; Cooper \& Withey, 2009; Deinzer et al., 1995; Edwards \& Templeton, 2005; Fleeson, 2004; Funder, 2006; Lewin, 1936; Magnusson, 1971; Mischel \& Shoda, 1995; Mischel, 2009; Rauthmann, 2011; Rauthmann et al., 2014; Reis, 2008; Shoda \& Mischel, 2000; van Mechelen \& De Raad, 1999; Wagerman \& Funder, 2009).

Remember Matt now: Maybe it is not the sports field that triggers his otherwise hidden side but his personal perception of the situation as, for example, highly irrelevant for his professional career as well as the perception of the physically demanding aspects of the game. 
The overlap of situational features perceived by most people allows defining situation characteristics on which the situations may be rated. As Edwards and Templeton (2005) describe it, situations may have characteristics in such a way as persons have traits. It is now the rating of a person on these dimensions that qualifies as his or her personal tendency to perceive such a situation. One may or may not understand why a person rates a situation in a certain way - this might depend on his or her history, personality, or current state, such as being hungry, angry or in a good mood. Yet, it can be examined how the perception of a certain situation does alter the person's behavior - in general as well as in a particular situation. General refers to a stable influence of the tendency to perceive different situations in the same certain way and a general tendency to exert certain behavior. Specific refers then to the effect of a specific situation - as perceived - on specific behavior in that particular situation.

It is furthermore of great advantage to have a measure of situation perception that lies within the person. No matter what the next situation will be, the personal tendency of that person to perceive situations in a certain way is supposed to stay the same. One critique of incorporating the situation into the equation for predicting behavior was that this only leads to fruitless point predictions, i. e. predictions of behavior of a certain person in a certain point in time (Hogan, 2009). This problem is avoided by measuring a general tendency of a person to perceive a situation. Within person variability of behavior that is so far unexplained by a person's trait may therefore be explained by the situation perception of a person.

Different researchers explored different situation dimensions within the last few years. Whereas some dimensions are based on ratings of different subjects in different situations (e. g. Magnusson, 1971; Sherman et al., 2010), others are located in the tradition of the lexical approach (e. g. Yang et al., 2006; Ziegler, 2014). A complete overview of the situation taxonomies is given by Rauthmann and colleagues (2014) as well as Yang et al. (2006) and shall not be repeated here. Since the current study is based on dimensions derived from the lexical approach, it will be presented in more detail.

\section{The Lexical Approach to Subjective Situation Perception}

The lexical approach is mostly related to the Big Five personality dimensions (John \& Srivastava, 1999, for a review with respect to examination of situations see Wagerman \& Funder, 2009). The lexical approach is based on the assumption that relevant descriptions of persons find their way into language (Allport \& Odbert, 1936; Deary, 2009). This may also be transferred to the description of situations: Their relevant features may also find their way 
into human language. Examining thus descriptions of persons or situations, one may find the underlying dimensions of human personality or situational taxonomies. Using the lexical approach to investigate subjective situation perception, Edwards and Templeton (2005) required respondents to complete the sentence "the situation was...". By means of factor analysis, they found the situational dimensions positivity, negativity, productivity and ease of negotiation. Note that this approach also belongs to subjective approaches to situational taxonomies, since the words used for sentence completion are already the result of what people perceived to be relevant of a situation.

For the construction of the B5PS, another example of the subjective approach, Ziegler (2014) extracted 15.000 adjectives from the Duden, a German spelling dictionary. Subjects were then asked to rate a random situation of their daily lives with a reduced number of adjectives. Using factor analyses, the ratings were finally reduced to five dimensions of situation description: Mental and physical load (MPL), cognitive load, monotony, expectation of results and vitality. ${ }^{2}$ This approach combines the lexical hypothesis with ratings of different persons across randomly selected situations. Every situation was only rated once (since they were based on self-selected, random situations), which shows that the dimensions can be found over a wide range of situations.

\section{Effects of General and Specific Situation Perception}

There is a very important distinction between a personality trait of a person and his or her tendency to perceive a situation, even though both are supposed to be stable within a person. A trait is seen as a disposition, which is stable over time (Johnson, 1999). The tendency to perceive a situation in a certain way, for example as imposing a high cognitive load, is also supposed to be stable over time and situations. The more one tends to perceive one situation as high in cognitive load, the more one tends to perceive other situations in a similar way. This will be the general situation perception tendency of a person. Yet the situation perception is also supposed to vary from one situation to another (since the situation changes); the trait (i.e. the stable disposition, by definition) is not. It is the variability in situation perception that is to account for the imperfect stability of the personality trait. This variability in situation perception will be referred to as the specific situation perception. Including this leads then to ipsative consistency and to a new understanding of a trait as "intra-individual consistencies and inter-individual uniquenesses in propensities to behave in

${ }^{2} \mathrm{~A}$ detailed description of the construction process of the questionnaire as well as an explanation of the dimensions is given in the method section. 
identifiable ways in light of situational demands" (Tett \& Burnett, 2003, p. 502), or as Rauthmann and colleagues put, it "how a situation is perceived will determine which behaviors and actions [...] are taken" (Rauthmann et al., 2014, p. 3, emphasis in original).

To conclude, the traits' manifestation in terms of behavior may vary from one situation to another. It is therefore reasonable to include the general as well as the specific situation perception into the prediction of behavior, as stated by Lewin with his equation in 1936.

Yet Lewin does not offer a theory linking the situation perception and the personality nor does he weigh their relative importance. A theory linking situation perception and personality traits is the Trait Activation Theory (TAT; Tett \& Burnett, 2003; Tett \& Guterman, 2000). According to the TAT, a trait may have an influence on behavior only in relevant situations (Kenrick \& Funder, 1988); since this relevance is subject to the individual's own situation perception, the trait expression may also alter from one situation to another, even if the environment seems objectively to be the same. The specific influence a certain situation has on a person's behavior (i. e. expression of the trait) is therefore different from case to case, as was also hypothesized by Lewin. Different cases may relate to different people yet also to different situations and, most importantly, to different combinations of traits and situation perceptions. This could also be formulated by so-called if...then contingencies as proposed by Mischel and colleagues (Shoda \& Mischel, 2000). If - and only if - the expression of a trait is perceived as relevant in a situation, then he or she will express a particular trait.

There are only very few reports on which personality dimension is influenced by which environment or situation (e. g. Sherman et al., 2010). Due to all this vagueness at this stage of examination, one may wonder about the different main effects of both the trait and the situation as well as their interaction on behavior. As was presented before empirically and is also agreed upon by both the advocates of the trait as well as the situation, at least traits do allow for prediction of behavior (Kenrick \& Funder, 1988; Tett \& Guterman, 2000).

Yet, the main effect of the situation in general is also agreed upon but much less examined than the main effect of traits on trait expression. The interaction of situation and trait within the same generalizable framework will thus to be further examined in this study. 


\section{Aim of the present Study}

The present study is designed to assess the role of personality and the environment as perceived by a person and their influence on behavior.

Following the theoretical argumentation, four hypotheses can be made. The first reflects the idea that a specific situation exerts an effect on a person's behavior as stated by the trait activation theory.

Hypothesis 1: The specific perception of a situation does influence the behavior in this particular situation.

The second hypothesis tests the assumption of different effects of the situation on behavior for each person:

Hypothesis 2: The effect tested in hypothesis 1 is different for different persons.

The third hypothesis tests a general assumption, namely that a person's trait will influence his or her behavior:

Hypothesis 3: The trait of a person influences his or her behavior across different situations.

Finally, the fourth hypothesis tests whether the general tendency to perceive a situation in a certain way can explain behavior:

Hypothesis 4: The general tendency of a person to perceive different situations in a certain way will influence his or her behavior.

In the next section, the B5PS (Ziegler, 2014) and its construction process, the dimensions of situation perception and personality traits will be presented. The theoretical assumptions and effects that were hypothesized will then be transferred to a multilevel model to examine each hypothesis separately (see Table 2). It is then the aim to assess what Lewin invited us to find: "concepts on the basis of which predictions can be made"(Lewin, 1936, p. 13). 


\section{Method}

\section{Big Five Inventory of Personality in Occupational Situations (B5PS)}

The B5PS questionnaire (Ziegler, 2014) was designed to make better predictions of behavior, such as career success, by measuring not only the Big Five personality domains but also dimensions of situation perception. For the Big Five personality domains, additional facets are also measured, yet they will not be further considered since they are not relevant to this study.

Big Five personality domains in the B5PS. The Big Five personality model is one of the major models for describing personality (Digman, 1990; Johnson, 1999). The model is based on the assumption that personality can be described with five broad domains, namely flexibility (openness to experience), conscientiousness, extraversion, team orientation (agreeableness) and resilience (neuroticism, reversely coded). Together they will be referred to as B5. For the current study, the names of the B5PS dimensions will be used; they do however correspond to the Big Five personality dimensions as indicated in brackets. The dimensions as measured in the B5PS are described in Table 1.

The items for the $B 5$ domains are in part based on the International Personality Item Pool (IPIP, 2015). By testing these items in American as well as German samples and means of confirmatory factor analysis, 211 items were selected to constitute the final test. As pointed out by the author, the items are formulated in a way relevant for occupational settings, thereby increasing the validity for predicting career success as well as the subjects' acceptance.

The domains of situation perception in the B5PS. The construction of the situation perception items is based in the tradition of the lexical approach. The author of the B5PS extracted about 15.000 words suitable for situation description from a German dictionary, reduced these to 3000 and then by the judgment of independent raters to 300 . In a next step, 521 German students were asked to rate a situation chosen by themselves on 75 of these 300 adjectives. An exploratory factor analysis was conducted on the first half of the data set. The structure was then assessed on the second half of the data set using a confirmatory factor analysis. The first analysis revealed seven domains of situation perception. After replicating the findings in another sample, one of the dimensions, environmental factors (i. e. the weather), was eliminated from further analysis, since it was not seen to have any incremental 
value to a description of a situation. Another one, valence, highly correlated with the remaining five dimensions and therefore was split into two higher order factors, strain and vigor. The remaining five dimensions are mental and physical load (MPL), cognitive load, monotony (under the higher order factor strain), expectation of results and vitality (under the higher order factor vigor), together referred to as S5. Descriptions of the five domains and their statistics can be found in Table 1. A total of 211 items was selected to measure the situation perception dimensions.

Table 1

Descriptive statistics and description of $B 5$ and $S 5$ dimensions.

\begin{tabular}{|c|c|c|c|c|}
\hline Dimension & Description & Descri & ive $\mathrm{s}$ & atistics \\
\hline & & $M$ & $S D$ & Alpha \\
\hline Big Five & Persons high on this domain... & & & \\
\hline $\begin{array}{l}\text { Flexibility } \\
\text { (Openness to } \\
\text { experience) }\end{array}$ & $\begin{array}{l}\text { are open to different opinions and ideas of } \\
\text { others, liberal-minded, interested in new } \\
\text { topics. }\end{array}$ & 4.35 & .45 & .90 \\
\hline Conscientiousness & $\begin{array}{l}\text { are well organized, ambitious, disciplined, } \\
\text { try to avoid mistakes. }\end{array}$ & 4.31 & .44 & .90 \\
\hline $\begin{array}{l}\text { Team orientation } \\
\text { (Agreeableness) }\end{array}$ & $\begin{array}{l}\text { do no like to speak badly of colleagues, } \\
\text { like to give positive feedback, are } \\
\text { appreciative and sincere. }\end{array}$ & 3.81 & .31 & .79 \\
\hline Extraversion & $\begin{array}{l}\text { like meeting new people, start } \\
\text { conversations easily, can direct a } \\
\text { discussion. }\end{array}$ & 4.00 & .53 & .92 \\
\hline $\begin{array}{l}\text { Resilience } \\
\text { (Neuroticism, } \\
\text { reversely coded) }\end{array}$ & $\begin{array}{l}\text { can cope easily with stress, are less } \\
\text { vulnerable to external stressors, not easily } \\
\text { upset. }\end{array}$ & 3.79 & .48 & .89 \\
\hline Situation Five & $\begin{array}{l}\text { Persons high on this dimension tend to } \\
\text { perceive situations... }\end{array}$ & & & \\
\hline $\begin{array}{l}\text { Mental and physical } \\
\text { load }\end{array}$ & $\begin{array}{l}\text { as burdening, physically demanding and } \\
\text { stressful. }\end{array}$ & 3.86 & .59 & .94 \\
\hline Cognitive load & $\begin{array}{l}\text { as cognitively demanding, taxing, complex } \\
\text { or unclear. }\end{array}$ & 3.83 & .39 & .83 \\
\hline Monotony & as boring, uninteresting and dull. & 3.60 & .49 & .90 \\
\hline $\begin{array}{l}\text { Expectation of } \\
\text { results }\end{array}$ & $\begin{array}{l}\text { as potentially rewarding and expect a } \\
\text { positive result, tend to see opportunities. }\end{array}$ & 4.20 & .44 & .91 \\
\hline Vitality & as lively and dynamic, turbulent and vivid. & 3.97 & .49 & .90 \\
\hline
\end{tabular}

Note. $M=$ mean, $S D=$ standard deviation, Alpha = Cronbach's Alpha.

The Big Five measured in a situation. Since the influence of the situation perception on the actual personality is to be measured, two items, one measuring the $B 5$, the other one measuring the $S 5$, are presented together in the following way: First, a brief description of a situation (called vignette) is presented, for example "You have just had your annual 
appraisal with your manager, in which you received a lot of detailed feedback. " A statement then appears and the person is asked to rate the situation on one of the $S 5$, in this case on cognitive load: "I assess this situation as challenging". Then the next statement is revealed, describing the behavior of the person as a rating of the Big Five, here flexibility: "I reflect on the feedback". This particular combination of each B5 with each S5 is repeated between eight and ten times, depending on the particular combination, which results in a total of 25 interactions. Overall, 211 vignettes along with 211 personality items and 211 situation perception items are presented. All items are presented on a computer screen and the person cannot skip an answer. They are rated on a 6-point Likert-scale, ranging from $1=$ strong disagreement to $6=$ strong agreement.

\section{Data Acquisition}

The sample used in this study is the norming sample of the questionnaire, which is selected to be representative of the German, Austrian and Swiss population of the year 2012 (Ziegler, 2014). 398 subjects completed the questionnaire in 2013 and 2014. Data acquisition took place in the test laboratories of Schuhfried GmbH in Mödling, Austria. The sample consists of 173 women (43\%) and 225 men (57\%), ranging from 17 to 69 years. The mean age was 42.03 years $(S D=13.91)$.

Data analysis was done using R (R Core Team, 2014). The multilevel model was calculated with the R package lme4 (Bates, Maechler, Bolker, \& Walker, 2014), descriptives and item statistics were calculated using the psych-package (Revelle, 2014). 


\section{Statistical Analysis}

Due to the nested structure of the data and predictors with different levels of aggregation, a multilevel model is applied (Snijders \& Bosker, 1999). Firstly, the variables in the model will be described. Secondly, the components of the model are related to the theoretical considerations. Finally, the structure of six nested multilevel models, each testing a different hypothesis or assumption, is presented.

Variables in the multilevel model. In this section, I will describe the variables used in the data analysis. An item consisted of a brief description of a situation, such as "You have just had your annual appraisal with your manager, in which you received a lot of detailed feedback. "This situation had then to be rated by the subject in a first step; in a second step, the subject indicated his or her hypothetical behavior.

PiS, Personality in Situation, is the hypothetical behavior of a person in a situation. For example, his or her rating of the statement "I reflect on the feedback". It is a hypothetical behavior for a person and at the same time it is a measure of the expression of a personality trait in that particular situation, hence Personality in Situation. For each personality domain, there are several measures per person in combination with different hypothetical situations. Therefore, each combination of $P i S$ is indexed by a $j$ for the person and $i$ for the specific item. $P i S_{i j}$ is thus the item $i$, measuring the hypothetical behavior $P$ in a hypothetical situation perceived on the dimension $S$ for the $j$-th person. In the following model, $P i S_{i j}$ is the dependent variable. Since there are several measures of $i$ nested in the person $j$, a multilevel model is applied. Thus, $P i S_{i j}$ is the level-1 dependent variable, which is predicted by the remaining variables.

$\mathrm{SiP}$, Situation in Personality. In the same hypothetical situation, the situation perception $S$ is measured, for example by the item "I assess this situation as challenging" 3 . For each item $P i S$, a partner item of the same vignette exists, $S i P$, which is therefore indexed in the same way: $S i P_{i j}$ is the item $i$ measuring situation perception $S$ in combination with an item measuring the hypothetical behavior $P$ for the person $j$. In the multilevel model, this item is the level-1 predictor and corresponds to the specific situation perception of a person.

$P_{j}$, Personality, is the score of the person $j$ on the personality domain $P$. This score is the average of all items $P i S_{i j}$ for each person $j$, for example the score of a person on the dimension team orientation. It is measured on the five dimensions of personality, described

\footnotetext{
${ }^{3}$ Note that this answer is given before the answer on the dependent variable $P i S_{i j \text {. }}$
} 
in Table 1. This variable is the level-2 predictor in the multilevel model (it only has a $j$, not an $i$ ). This level-2 variable is grand mean centered for each person $j$, making the estimation of the model easier, which is due to the reduced correlations among predictors as well as among the fixed effects (Enders \& Tofighi, 2007; Hox, 2010).

$S_{j}$, Situation Perception, is the score of a person $j$ in the domain of situation perception $S$. It is the average of all items $\mathrm{SiP}_{i j}$ for each person $j$, for example the score of a person on the dimension expectation of results. This variable is the second level-2 predictor in the model and is also grand mean centered. The situation perception corresponds to the general tendency of a person to perceive different situations in a certain way and is on the five dimensions of situation perception described in Table 1 .

\section{Lewin and the Multilevel Model}

A statistical model in general should reflect the data generating process as accurately as possible (Dumenci, 2000). Since the data generating process should be reasonably well approximated by the theory given above, the hypotheses should also be transferable to a statistical model. Following Lewin and the theoretical arguments above, the hypothetical behavior in a particular situation $\left(P i S_{i j}\right)$ is the result of the perception of that situation and the personality of a person. Each component of the following model tests an assumption or hypothesis of the theoretical discourse.

The structure of the data with items being nested in persons and additional level-2 predictors requires a multilevel model. Five dimensions of situation perception are combined with five dimensions of personality each, resulting in a total of 25 models to be tested. The model notation is the same used in standard books of multilevel modeling by Hox (2010) and Snijders and Bosker (1999).

Each of the variables described above and additional effects are entered in the model separately, as recommended by Bliese (2002). This step-by-step extension of the models, i. e. their nested structure, allows comparing these models based on a likelihood ratio test (Hox, 2010; Snijders \& Bosker, 1999). The utility to increase model fit of the next predictor is thereby assessed. An overview of all the models and the variables included per model is given in Table 2 . 
Table 2

Formal representation of multilevel models and tested effects.

\begin{tabular}{|c|c|c|}
\hline Model & $\begin{array}{l}\text { Hypothesis / } \\
\text { effect tested }\end{array}$ & Formal Representation \\
\hline \multirow[t]{2}{*}{$\begin{array}{l}\text { (1) } \\
\text { Intercept Only } \\
\text { Model } \\
\text { [Int.] }\end{array}$} & $\begin{array}{l}\text { Variability of } \\
\text { average L-1 DV } \\
\text { between persons }\end{array}$ & $\begin{aligned} P i S_{i j} & =\beta_{0 j}+e_{i j} \\
\beta_{0 j} & =\gamma_{00}+u_{0 j} \\
P i S_{i j} & =\gamma_{00}+u_{0 j}+e_{i j}\end{aligned}$ \\
\hline & $\begin{array}{l}\text { General L-1 model } \\
\text { following models: }\end{array}$ & $P i S_{i j}=\beta_{0 j}+\boldsymbol{\beta}_{1 j} \boldsymbol{S i} \boldsymbol{P}_{i j}+e_{i j}$ \\
\hline $\begin{array}{l}\text { (2) } \\
\text { Random Intercept } \\
\text { Model } \\
\text { [L1SiP, ri] }\end{array}$ & $\begin{array}{l}\text { H1: Prediction } \\
\text { of behavior with } \\
\text { specific situation } \\
\text { perception }\end{array}$ & $\begin{aligned} \beta_{0 j} & =\gamma_{00}+u_{o j} \\
\beta_{1 j} & =\gamma_{10} \\
P i S_{i j} & =\gamma_{00}+\gamma_{10} \boldsymbol{S i P}_{i j}+u_{o j}+e_{i j}\end{aligned}$ \\
\hline $\begin{array}{l}\text { (3) } \\
\text { Random Slopes } \\
\text { Model } \\
{[\mathrm{L} 1 \mathrm{SiP}, \mathrm{rs}]}\end{array}$ & $\begin{array}{l}\text { H2: Random } \\
\text { slopes for each } \\
\text { person }\end{array}$ & $\begin{aligned} \beta_{0 j} & =\gamma_{00}+u_{o j} \\
\beta_{1 j} & =\gamma_{10}+\boldsymbol{u}_{1 j} \\
P i S_{i j} & =\gamma_{00}+\gamma_{10} S i P_{i j}+\boldsymbol{u}_{1 j} \boldsymbol{S i} \boldsymbol{P}_{i j}+u_{o j}+e_{i j}\end{aligned}$ \\
\hline $\begin{array}{l}\text { (4) } \\
\text { Level } 2 \text { Predictor } \\
\text { of Random } \\
\text { Intercepts } \\
\text { [L2B5] }\end{array}$ & $\begin{array}{l}\text { H3: Prediction } \\
\text { of variability in } \\
\text { L-1 DV with L- } \\
2 \text { B5 }\end{array}$ & $\begin{aligned} \beta_{0 j}= & \gamma_{00}+\gamma_{\mathbf{0 1}} \boldsymbol{B} \mathbf{5}_{j}+u_{o j} \\
\beta_{1 j}= & \gamma_{10}+u_{1 j} \\
P i S_{i j}= & \gamma_{00}+\gamma_{\mathbf{0 1}} \boldsymbol{B} \mathbf{5}_{j}+\gamma_{10} S i P_{i j}+u_{1 j} S i P_{i j} \\
& +u_{o j}+e_{i j}\end{aligned}$ \\
\hline $\begin{array}{l}(5) \\
\text { Level } 2 \text { Predictor } \\
\text { of Random } \\
\text { Intercepts } \\
\text { [L2S5] }\end{array}$ & $\begin{array}{l}\text { H4: Prediction } \\
\text { of variability in } \\
\text { L- } 1 \text { DV by L-2 } \\
B 5 \text { and } S 5\end{array}$ & $\begin{aligned} & \beta_{0 j}= \gamma_{00}+ \\
& \beta_{1 j}=\gamma_{01} B 5_{j}+\gamma_{\mathbf{0 2}} \boldsymbol{S} \mathbf{5}_{\boldsymbol{j}}+u_{o j} \\
& P i S_{i j}=\gamma_{00}+ \gamma_{01} B 5_{j}+\gamma_{\mathbf{0 2}} \boldsymbol{S} \mathbf{5}_{\boldsymbol{j}}+\gamma_{10} S i P_{i j} \\
&+u_{1 j} S i P_{i j}+u_{o j}+e_{i j}\end{aligned}$ \\
\hline $\begin{array}{l}\text { Level } 2 \text { Predictor } \\
\text { of Random Slopes } \\
{[\mathrm{B} 5 \mathrm{xSiP}]}\end{array}$ & $\begin{array}{l}\text { Prediction of } \\
\text { random slopes } \\
\text { with L-2 B5 }\end{array}$ & $\begin{aligned} \beta_{0 j}=\gamma_{00}+ & \gamma_{01} B 5_{j}+\gamma_{02} S 5_{j}+u_{o j} \\
\beta_{1 j}=\gamma_{10}+ & \gamma_{11} \boldsymbol{B} \mathbf{5}_{j}+u_{1 j} \\
P i S_{i j}=\gamma_{00}+ & \gamma_{01} B 5_{j}+\gamma_{02} S 5_{j}+\gamma_{10} S i P_{i j} \\
& +\gamma_{11} \boldsymbol{B} \mathbf{5}_{j} \boldsymbol{S i} \boldsymbol{P}_{\boldsymbol{i j}}+u_{1 j} S i P_{i j}+u_{o j} \\
& +e_{i j}\end{aligned}$ \\
\hline
\end{tabular}

Note. $\mathrm{DV}=$ dependent variable, $S 5=$ situation perception dimension, $B 5=$ big five personality dimension, $\mathrm{L}-1=$ level-1, L-2 = level-2, $i=$ item, $j=$ person, $P i S_{i j}=$ item measuring personality $P$, in a vignette with situation perception $\mathrm{S}, S i P_{i j}=$ item measuring situation perception $S$, in a vignette with personality $P . \gamma_{00}=$ mean intercept, $\gamma_{01}=$ mean slope for personality, $\gamma_{02}=$ mean slope for situation perception, $\gamma_{10}=$ mean slope for the level-1 situation perception, $\gamma_{11}=$ mean slope for the cross level interaction, $u_{o j}=$ person specific deviation of intercept from fixed intercept $\left(\gamma_{00}\right), u_{1 j}=$ person specific deviation of slope from fixed slope $\left(\gamma_{10}\right), e_{i j}=$ person and item specific residual. Effects added and tested per equation are in bold. Abbreviations in square brackets correpsond to model names in Figure 1 and Table 3.

Six nested multilevel models. The first of the six models is the intercept only model (or empty model), allowing between-person variability of intercepts across persons. For each person $j$, the average of all items $P i S_{i j}$ in one of the personality dimensions $P$ that are measured in combination with situation perception $S$ is calculated and their variability is 
tested. This is the baseline model to which the next model in the hierarchy will be compared. There is no predictor (that is, no slope, hence intercept only model) included in this model, only the dependent variable, $P i S_{i j}$. This model tests the assumption that there is sufficient variability between the persons that can be predicted, which is a prerequisite for the further analysis (LaHuis \& Ferguson, 2007).

The second model is the random intercept (fixed slope) model with the first level-1 predictor specific situation perception included. In this model, each value of variable $P i S_{i j}$ is predicted by a corresponding value $S i P_{i j}$. The intercepts may vary for each person $j$, the slopes for the regressions lines are the same for each person. By comparison of the first and the second model it can be tested if there is an influence of the situation perception on the hypothetical behavior in that situation. This influence is, however, fixed to be equal across all persons $j$. This tests the first hypothesis, which states that the specific situation perception affects behavior in this situation.

The third model is a random intercept, random slope model. In addition to the random intercepts that are estimated differently per person, each person $j$ may now have his or her own slope. Comparing the third and the fourth model tests the assumption of a different effect (for each person $j$ ) of the situation perception on the hypothetical behavior. This tests hypothesis two, which assumes that the effect of the specific situation perception on behavior is different for each person. There is yet no explanation for these effects in the model (this will be included in model six). Even if this hypothesis would not hold, it could nevertheless be preceded with model four and five, since they do not rely on the existence of random slopes, predicting only the random intercepts.

In the fourth and fifth model the overall personality of the person $j, B 5_{j}$, and the general situation perception of person $j, S 5 j$, are included as level-2 variables to predict the random intercepts. In the fourth model, hypothesis three is thereby tested, which assumes an influence of personality on the hypothetical behavior. Since the scores on $P i S_{i j}$ are part of the predictor, an autocorrelation is to be expected. Therefore a positive significant effect across all 25 interactions is hypothesized. It is nevertheless important to include this predictor in the model in order to estimate the effect of the situation perception dimension after controlling for the influence of the personality dimension.

In the fifth model, the general influence of the general situation perception tendency, $S 5_{j}$, on the hypothetical behavior in a certain situation is tested, which directly relates to hypothesis four, an effect of the general situation perception on behavior. For example, it may be tested whether persons high on team orientation tend to perceive situations generally 
as animated. A significant effect in the fifth model means that a general effect of the situation perception across all situations on the hypothetical behavior across all situations exists and that this effect exists even after controlling for the level-2 personality as well as the level-1 predictor specific situation perception.

In the sixth and last model, the overall personality of a person $j, B 5_{j}$, is included in the model as a predictor of the random slopes. This is a cross-level interaction. For example, subjects high on team orientation might show a higher relationship between the (hypothetical) team oriented behavior in a certain situation and the perception of the same situation as, say, monotonous. These effects are speculative and shall be investigated in an explorative manner and are therefore not reflected in any hypothesis. Even though it is theoretically possible to test a cross-level interaction when the inclusion of random slopes did not increase the model fit (LaHuis \& Ferguson, 2007), the cross level-interaction will only be considered relevant when also the inclusion of random slopes was of importance in the third model.

Overall, six models are calculated and compared for each of the 25 combinations of $S 5$ and $B 5$, resulting in 125 models. Each combination tests the four hypotheses and the explorative cross-level interaction. Using this multilevel approach, it is possible to decompose the overall effect of the situation perception on behavior into a specific effect and a general effect. It furthermore allows to tests the effect of general situation perception after controlling for the specific effect of situation perception and the effect of overall personality on hypothetical behavior.

\section{Significance of Fixed and Random Effects}

For some estimated models (i. e., model two to six), the $t$-values of the fixed effects give an insight into whether an effect is significant as well as direction of that particular effect. For a simpler presentation, $t$-values exceeding $t=|10|$ were transformed according to the following equation:

$$
t_{\text {trans }}=\left\{\begin{aligned}
t, & t<|10| \\
10+\log (t), & t>10 \\
10+(-\log (|t|), & t<-10
\end{aligned}\right.
$$

Large $t$-values were thereby reduced and the range of the y-axis (Figure 1) could be decreased.

The test of significance for fixed effects in multilevel models is complex due to the estimation of degrees of freedom at varying levels of the model (Pinheiro \& Bates, 2000). 
The simplest test is the Wald $Z$ test (Wald, 1943), based on the parameter estimates and their standard errors. An effect is considered significant at the 5\% level when the ratio of these two values exceeds $|t|>1.96$. For large sample sizes with more than 100 level-2 variables, this is a valid test, especially when one is interested in the fixed effects (Hox, 2010; Maas \& Hox, 2005). For assessing the significance of the fixed effects, this method will therefore be applied.

For the assessment of the significance of random effects, no $t$-statistics are provided. Yet the nested structure of the models allows comparing the models using a likelihood ratio test (Hox, 2010; Snijders \& Bosker, 1999). Each model was compared to its previous one and the improvement of model fit was assessed. An effect is considered to be significant when $p \leq$ .05 . The assessment of the significance of the random effects is solely based on this likelihood ratio test. 
Table 3 shows the results of the likelihood ration test of model comparison. Each model is compared to its previous one (that is, model 2 to model 1, model 3 to model 2, etc.). An effect is considered significant when $p<.05$. A significant effect indicates that the extension of the model by the respective predictor/effect does improve the fit.

\section{Fixed effects of the Models}

Figure 1 shows the fixed effects of the multilevel models. The models displayed are the fourth model (random intercept, random slope and level-2 personality as predictor, solid line), the fifth model (level-2 general situation perception added as a predictor, dashed line, long dashes) and the sixth model (cross level interaction added, dashed line, short dashes). A value represents the transformed $t$-value of the corresponding fixed effect. The grey area is the area of insignificance, ranging from $t=-1.96$ to $t=1.96$. Values in this area are not significant on the $5 \%$ level; values outside this area are significant.

For one line, each dot represents the $t$-value of the fixed effect denoted on the x-axis (they also correspond to the particular model with the exception of the random slopes and random intercept model). Comparing three effects of three different models, that is, comparing the three different lines, gives an insight into whether the fixed effects change when a new effect/predictor is added. For all models, the effect of a particular predictor stays the same or gets smaller, yet an effect is never reversed nor reduced to insignificance when a new predictor or effect is added. 4

The asterisks under each model represent the results from the likelihood ratio test from left to right for each panel. They are an exact copy of the results from Table 3. Each column of asterisks belongs to a model that corresponds to the predictor denoted on the x-axis. For the random intercepts and random slopes, two additional columns were added ( $r i$ and $r s$, respectively).

\footnotetext{
${ }^{4}$ This is also true for the models that are not displayed: The empty model, the random intercept and random slope model.
} 

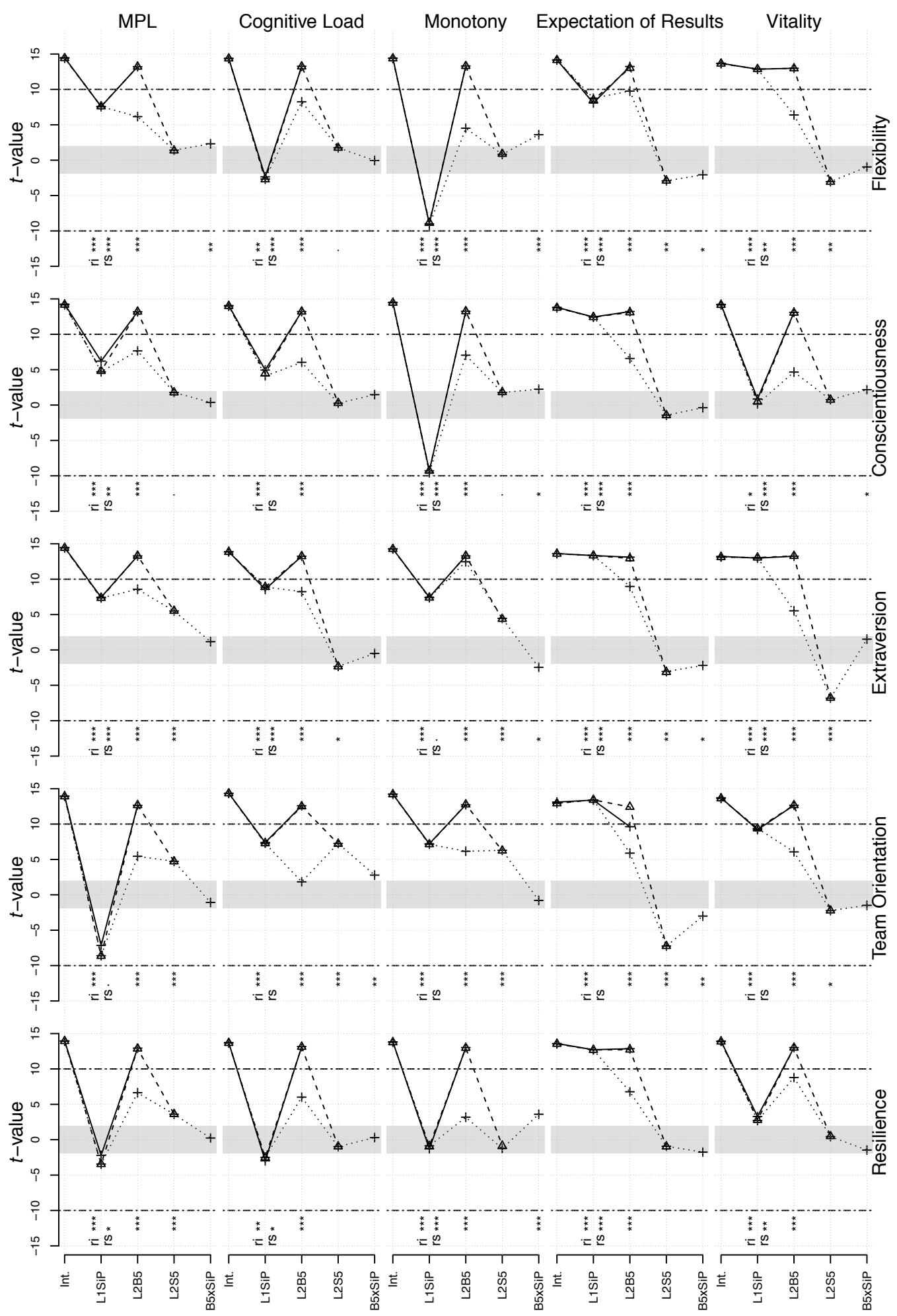

Figure 1. $t$-values of the fixed effects for three models. Each panel represents the combination of a $S 5$ dimension (row-wise) with a $B 5$ dimension (column-wise). Each line in a panel connects the $t$-values of the fixed effects of one model: solid line - fourth model; dashed line - fifth model; dashed line - sixth model (for descriptions see Table 2). The corresponding effects are listed on the x-axis: Int. = Intercept; L1SiP = level-1 predictor SiP; L2B5 = level-2 predictor B5; L2S5 = level-2 predictor S5; B5xSiP = Cross-level interaction of $B 5$ with $S i P$. $t$-values exceeding $|10|$ were transformed (see text). Asterisks denote the significance of the likelihood ratio test (Table 3) from left to right within each panel, corresponding to the model and effect denoted on the x-axis, with exception of the random intercept (ri) and random slope (rs) models, that are listed separately. Significance codes: $* * * p<.001, * * p<0.01, * p<.05, . p<.10$. 


\section{Evaluation of Hypotheses}

Figure 1 presents 25 different interactions of situation perception and a personality domain of the Big Five. Some of these interactions are similar to each other, which will be pointed out in the following section.

Prerequisite: Random Intercepts. It can be seen that for each interaction the fixed effect of the intercept is significant. This indicates that people significantly differ in their average hypothetical behavior across several situations. This is also a prerequisite for the further analysis and prediction of random intercepts (LaHuis \& Ferguson, 2007).

Hypothesis 1: The specific perception of a situation does influence the behavior in this particular situation. For each model, the inclusion of the level-1 predictor specific situation perception, $S i P_{i j}$, significantly improved the model fit for all models. Compared to the intercept only model, this means that there is a significant relationship between the perception of a hypothetical situation and the hypothetical behavior in that situation.

Hypothesis 2: The effect tested in hypothesis 1 is different for different persons. The inclusion of random slopes for the relation between the level-1 predictor specific situation perception and the level-1 criterion hypothetical behavior was significant for 19 of the 25 models. It is of particular interest that five of these insignificant random slopes models (see Table 3) all belong to the B5 domain team orientation. According to this finding, the relationship between team oriented behavior in a situation and the situation perception of that situation therefore seems to be the same for all people (even though it may be different for each situation perception dimension). The sixth model for which the random slopes did not improve model fit compared to the intercept only model is the model of conscientiousness and cognitive load. Assuming the same relation for all people does not seem to decrease model fit compared to assuming a different relationship for each person.

\section{Hypothesis 3: The trait of a person influences his or her behavior across different} situations. The inclusion of the level- 2 predictor personality as a $B 5$ domain, $B 5_{j}$, improved all model fits for all 25 interactions. This was expected, since the items that are predicted are also part of the regressor and predicting the answers on one domain with answers of the same domain on the same questionnaire should be significant. 
Hypothesis 4: The general tendency of a person to perceive different situations in a certain way will influence his or her behavior. The inclusion of the level-2 predictor general situation perception did improve the model fit for 13 out of 25 models. Of these 13 models, eight were of the interaction of the situation perception dimensions expectation of results and vitality with flexibility, extraversion, team orientation. Six of the remaining seven were the interactions of the $B 5$ extraversion and team orientation with the remaining situation perception dimensions, i. e. mental and physical load, cognitive load and monotony. The last model was the interaction of resilience and mental and physical load. It is thus important to note that the model fits that were significantly improved by the inclusion of the level-2 predictor situation perception did all either include expectation of results and vitality or team orientation and extraversion (with one exception, resilience and mental and physical load).

Exploration: Prediction of Random Slopes. Finally, the inclusion of the level-2 predictor personality as a predictor of the random slopes improved the model fit for 10 out of 25 models. For two of these models the random slope did not improve the model fit significantly, they therefore will not be considered. For the remaining models, the different relationship for each person between the level-1 predictor situation perception and the level-1 criterion hypothetical behavior could be predicted by the level-2 predictor personality. These eight models were the interaction of mental and physical load with flexibility, monotony with flexibility, conscientiousness, extraversion and resilience, expectation of results with flexibility and extraversion and finally the interaction of vitality and conscientiousness.

\section{Examination of Specific Effects}

Figure 1 presents not only the $t$-values of the fixed effect but also the direction of the effect, that is, effects above zero on the y-axis are positive, effects below zero are negative. Two models will now be presented exemplarily for a more detailed understanding of the directions of the effects, on which no specific hypothesis was made. The first is the model of resilience with mental and physical load; the second is the combination of extraversion with expectation of results (see Figure 1, fifth row, $1^{\text {st }}$ panel and third row, $4^{\text {th }}$ panel from the left). The results from the first model have to be read as follows:

For the second example, mental and physical load and resilience, the inclusion of random intercepts and random slopes is significant $\left(\chi^{2}(1)=57.72, p<.001\right.$ and $\chi^{2}(2)=8.13$, $p<.05)$, and the corresponding fixed effect is negative $(t=-3.44)$. Subjects that tend to perceive a specific situation as more mentally and physically demanding tend to show less 
resilient behavior, and this effect is different for different persons (hypotheses 1 and 2). On the item level, this would for example correspond to the following vignette "Your computer has just crashed yet again and once again you haven't been able to save all the things you were working on " and the items "I assess the situation as laborious " (mental and physical load) and "I don't immediately burst into tears " (resilience).

The inclusion of the level-2 predictor resilience led to an improvement of the model fit $\left(\chi^{2}(1)=316.67, p<.001\right)$ and was positive $(t=6.64)$. People scoring higher on resilience are also more likely to show resilient behavior (hypothesis 3 ). The inclusion of the level-2 predictor general situation perception also led to an improved model fit $\left(\chi^{2}(1)=13, p<.001\right)$, yet with a positive effect $(t=3.60)$. People that tend to perceive situations in general as more mentally and physically demanding tend to show more resilient behavior, after controlling for the effect of the specific situation perception and resilience. The inclusion of the level-2 predictor resilience for the random slopes was not significant $\left(\chi^{2}(1)=.06, p=.81\right)$. There is no different effect of perceived mental and physical demand on resilient behavior for people scoring high or low on resilience $(t=0.24)$.

For the second example (extraversion and perceived expectation of results) the inclusion of random intercepts and random slopes for predicting extraverted behavior is significant $\left(\chi^{2}(1)=1113.04, p<.001\right.$ and $\left.\chi^{2}(2)=49.58, p<.001\right)$, yet the corresponding fixed effect is positive $(t=28.35)$. Persons with a stronger tendency to perceive a situation as high on expectation of results show more extraverted behavior (hypotheses 1 and 2). The inclusion of the level-2 predictor extraversion is also significant $\left(\chi^{2}(1)=386.51, p<.001\right)$, persons scoring high on extraversion show more extraverted hypothetical behavior $(t=8.97$, hypothesis 3). The inclusion of the level-2 predictor situation perception did also improve the model fit $\left(\chi^{2}(1)=9.75, p<.01\right)$, yet with a negative effect $(t=-3.05)$. Persons that tend to perceive different situations as high on expectation of results also tend to show less extraverted behavior, after controlling for the effect of extraversion and the specific perception of that situation (hypothesis 4). The inclusion of the level-2 predictor extraversion for predicting the random slopes did also improve model fit significantly $\left(\chi^{2}(1)=4.77\right.$, $p<.05)$, with a negative effect $(t=-2.19)$. Thus, the effect of level-1 situation perception on level-1 hypothetical extraverted behavior was lower for persons scoring high on extraversion than for those scoring low on extraversion.

Effect of level-1 predictor specific situation perception. A negative fixed effect of the level-1 predictor situation perception within a situation occurred in 11 of 25 models, all of 
which are in the first three columns of Figure 1, that is in a model with the situation perception dimension mental and physical load (MPL), cognitive load and monotony. For all these models, perception of the situation as high on MPL, cognitive load and monotony resulted in reduced expression of the $B 5$ personality domain, within this particular situation (since it is an effect on level 1).

A positive effect of the level-1 predictor, as in the second example, occurred in 12 of 25 models. The first was in the combination of MPL and conscientiousness, two in the combination of cognitive load with conscientiousness and extraversion. The remaining nine occurred all in the combination of expectation of results and vitality with the Big Five. Perceiving situations high on these dimensions results in higher expression of level-1 hypothetical behavior.

Effects of level-2 predictor general situation perception on random intercepts. The level-2 predictor general situation perception had a positive significant effect in six of 25 models. Two were the combination of extraversion with monotony and $M P L$, three in the combination of MPL, cognitive load and monotony with team orientation and one in the combination of $M P L$ with resilience. For these combinations, a tendency to generally perceive different situations as high on the respective six dimensions leads to an increased expression of the respective trait across different situations, after controlling for the effect of the level-2 predictor personality.

A negative effect of the level-2 predictor situation perception was found for seven models. These were the combinations of flexibility, extraversion and team orientation with expectation of results and vitality as well as the combination of extraversion and cognitive load. For these combinations, a tendency to perceive different situations as high on the respective dimensions leads to a decreased expression of the respective trait across different situations, after controlling for the effect of the level-2 predictor personality.

\section{Effects of level-2 predictor general situation perception on random slopes. A} positive effect of the level-2 predictor for the random slopes was found for five models. These were flexibility with monotony and MPL, conscientiousness with monotony and vitality, team orientation with cognitive load and resilience with monotony. For these models, an increase in the level-2 predictor $S 5$ led to an increased effect of the level-1 effect of situation perception within a situation on the specific expression of hypothetical behavior in that particular situation. For example, someone scoring high on flexibility has a higher effect 
of perceived monotony in a situation on his or her hypothetical open behavior than someone scoring lower on flexibility in the same situation.

A negative effect of the level-2 predictor for the random slopes was found for two models ${ }^{5}$ : Flexibility with expectation of results and extraversion with expectation of results. For these models, an increase in the level-2 predictor personality leads to a decreased effect of the level-1 predictor situation perception on the level-1 criterion hypothetical behavior.

\footnotetext{
${ }^{5}$ For the other models, the inclusion of the random slopes was not significant.
} 


\section{Discussion}

The current study investigated Lewin's Equation using a new questionnaire and a multilevel approach to model different effects personality and situation perception have on the hypothetical behavior of a person. It was explorative in parts, since no prediction of the direction of the effect could be made in advance.

\section{Assessing Lewin's Equation $-\mathrm{B}=\boldsymbol{f}(\mathrm{PE})$ ?}

After having assessed four different hypotheses, one can conclude that there is an effect of the specific situation perception on hypothetical behavior (hypothesis 1), that this effect is different for different persons (for 19 out of 25 models, hypothesis 2), that there is an effect of the personality on hypothetical behavior (for all models, hypothesis 3 ) and that, for 13 out of 25 models, the general situation perception influenced the hypothetical behavior, after controlling for the other effects (hypothesis 4). This leads to the conclusion that empirical support for Lewin's Equation can be provided. This important finding can lead to a reestablishment of the Equation as a valid framework for the further examination of factors that influence human behavior.

The individual effects assessed within the overall research question will now be given further consideration, as well as some other effects that were not hypothesized. These include the different effects the situation perception exerts on different levels (general vs. specific situation perception) as well as an emerging pattern of the influence and direction of $S 5$ on $B 5$ dimensions. Finally, the effect of the general situation perception on hypothetical behavior (hypothesis 4) was found for some Big Five dimensions (extraversion and team orientation), whereas it was less consistently found for other big five dimensions (conscientiousness and resilience).

\section{Specific and General Effect of Situation Perception (Hypotheses 1 \& 4)}

First of all, it can be noted that an effect of the specific situation perception exists in all models. The effect of the general situation perception, however, is not persistent across all models. The specific effect of the situation as perceived reflects the assumption of the advocates of the situation side of the person-situation debate, namely that the situation and its perception influences behavior.

For 13 out of 25 models, the general situation perception also had an effect on behavior, after controlling for the specific situation perception and the subject's personality. This 
indicates that behavior is - regardless of the specific situation - influenced by a general tendency of the subject to perceive these situations. This effect will be discussed in detail in the next section.

For these 13 models, the effect of the specific situation perception (hypothesis 1) and the level-2 effect of the general situation perception (hypothesis 4) are reversed. It is possible that this exceptional finding is due to miss-specified models. Yet the fact that this finding does not occur in all 25 models as well as its theoretical interpretability supports its interpretation as a valid effect. Conceptually, the specific and the general situation perception are different: The effect of specific situation perception reflects the effect of the current situation on behavior, whereas the effect of the general situation perception reflects a relationship of two variables that lie within the person. A person has a general tendency to perceive a situation as high or low on cognitive load or expectation of results. Since the examined dimensions are independent from each other, it will be difficult to present a general explanation (apart from a methodological artifact). For the already examined example of mental and physical load and resilience, a negative effect of the level-1 predictor, perception of a situation as high or low on mental and physical load on the dependent variable resilience was found. The more someone perceives a situation to be high on this dimension, the less resilient behavior he or she shows. The effect of the level-2 predictor however was positive. The more a person has the tendency to perceive situations in general as high on mental and physical load, the more he or she will exhibit resilient behavior. As can be seen, these effects are conceptually different and support the relevant distinction of specific and general situation perception.

It is beyond the scope of this study to investigate all other 12 models for which the general as well as the specific situation perception contributed significantly to the prediction of behavior. Note that, for the purpose of this article, it is important to distinguish between the two effects of situation perception and acknowledge their respective influence on behavior.

\section{Effect of General Situation Perception (Hypothesis 4)}

The level-2 effect of situation perception on the Big Five personality dimensions is to be understood as a general effect, which is by its very nature not situation specific. Extraversion and team orientation are affected by the general situation perception (for the results of the specific effects, see above), whereas conscientiousness and resilience are not affected by the general situation perception (flexibility is only affected by the so called vigor factors, not by the strain factors, see below). One may conclude that conscientiousness and resilience are 
more stable than extraversion and team orientation. This is, however, not a valid conclusion: They are only unaffected by the situation perception, yet they may nevertheless be equally stable. Results of other studies also do not support this conclusion (Viswesvaran \& Ones, 2000).

DeYoung (2006) provides another possible explanation. He found two higher order factors for the Big Five personality dimensions: Stability for the factors agreeableness (team orientation), conscientiousness and neuroticism (resilience) and plasticity for the dimensions openness/intellect (flexibility) and extraversion. The stability factors are "needed to maintain a stable organization of psychosocial function" (p.1149), whereas the plasticity factors help to explore the world and incorporate novel information. Since they depend on the received information from different environments, they can only fulfill their task so long as they are flexible enough to react to the different environments. The plasticity factors should thus be influenced by the general situation perception tendency. This is true for extraversion and partially true for flexibility (openness/intellect, influenced by two of the S5). The stability factors should be less influenced by the general situation perception: This is true for conscientiousness and resilience (neuroticism, reversed), yet it is not true for team orientation (agreeableness, which is influenced by the general situation perception). Further research can investigate this theory on an individual level by using for example factor scores of the plasticity and stability factors of each person to predict individual random slopes (level-1). Subsamples might be defined that do show the higher order structure and others that don't, depending on their relative position on each of the $S 5$ dimensions. It may further be possible that these findings can provide an alternative explanation for the two higher order factors found by DeYoung: Namely that they emerge due to the fact that their subordinate factors are equally influenced by the general situation perception. This question needs to be further addressed in subsequent research.

\section{No Random Slopes for Team Orientation (Hypothesis 2)}

Inclusion of random slopes in the models did improve the model fit for almost all models but the ones including team orientation (see Table 3, model two vs. model three) as well as the combination of cognitive load and conscientiousness. If the inclusion of the random slopes is not significant, the effect of the level-1 predictor situation perception on the behavior in the situation is the same for each person (Hox, 2010). Since the effect occurs across five independent analyses (no level-1 item is included in more than one model), the effect may be stable for team orientation and all $S 5$ dimensions. If one were to accept the 
effect as a true (as opposed to a method-)effect, a sound explanation should be presented, which this study cannot offer empirically. There is no factor within this analysis that distinguishes all the models without random slopes from the other 19 models.

One possible explanation is the strong situation hypothesis, which states that strong situations have the same effect on each person perceiving this situation (Mischel, 1977). Even though this theory was criticized (Cooper \& Withey, 2009), it may nevertheless be a starting point for an explanation. The level of agreeable behavior of the subjects across different situations can be different, but the effect of the situation on this behavior is the same for all subjects. This may then lead to a new understanding of a strong situation: It may not require all subjects to behave the exactly the same. It rather has the same effect on each person on his or her behavior. As these results furthermore suggest, this is less dependent on the actual situation than on the particular - team oriented - behavior.

\section{The Search for Level-2 Predictors for the Random Slopes}

For 19 out of the 25 models the random slopes were significant at $p<.05$. The level-2 predictor personality was, however, only seldom a valid predictor of the random slopes. Varying random slopes denote a different effect of the situation perception on the hypothetical behavior in one situation for each person. That is, for some persons the effect of the situation as perceived on their behavior is stronger than for others. Two questions follow from this finding: Firstly, is the susceptibility of behavior to the perceived situation a stable characteristic for each person? Some persons may be more affected by the situation in their behavior than others, across different situations and combinations of $S 5$ and B5. Secondly, assuming that this susceptibility is a stable characteristic of a person in the same way that within-person variability is a stable characteristic (Funder, 2009), it may be very interesting to identify variables that allow a better prediction of this characteristic. The within-person variability may thereby not only be accounted for, as requested by Bem and Allen (1974), but also be predicted. In the current framework, this could be possible by identifying a level-2 predictor, which predicts the random slopes equally well in all 19 models.

There may be, for example, a different effect for a specific sample, such as individuals with anxiety disorder. Since they "appraise situations as more threatening compared to controls" (Craske et al., 2009, p. 1076), this effect should manifest itself in some of the situation perception dimensions and thus in the effect on hypothetical behavior, and an anxiety score might be a valid level-2 predictor of the random slopes for the resiliencemodels. One may even go a step further and replace anxiety scores as level-2 predictors of 
random slopes with measures from anxiety related neurological transmitters, such as Gammaaminobutyric acid, GABA, which is an important anxiety related neurotransmitter (Lydiard, 2003). The same approach might be taken to investigate person with obsessive-compulsive disorders and the relation of the $S 5$ and conscientiousness (Samuel \& Widiger, 2011).

\section{Strain vs. Vigor Factors and their Respective Influence.}

Ziegler (2014) finds two super-factors for the situation five, strain for $M P L$, cognitive load and monotony, and vigor for expectation of results and vitality. Even though Ziegler (2014) hesitates to assign too much value to these factors unless they will be validated in another sample, the domains of the factors have a particular effect within this study.

The fixed effect of the level-1 predictor expectation of results and vitality were positive for all personality dimensions, except the combination of conscientiousness and vitality. These vigor factors therefore seem to enhance the expression of the $B 5$ personality dimensions in each situation. The fixed effect of the level-1 predictor was negative though for $M P L$, cognitive load and monotony (the strain factors) for 11 out of 15 possible combinations.

One way to interpret this effect is that the strain factors do mostly reduce the expression of the $B 5$ personality dimensions within each situation. A person perceiving a specific situation high on mental and physical load, cognitive load or monotony reduces the expression of his or her trait on nearly all personality dimensions. Conscientiousness however is enhanced by the perception of a situation as high on MPL and cognitive load.

Conscientiousness is, for example, related to coping strategies based on problem solving (Connor-Smith \& Flachsbart, 2007). It may therefore be the individual's reaction to the raised demands of the situation (Vollrath, 2001). One mechanism relevant for this relation could be desire for structure, which is also related to conscientiousness (Neuberg \& Newsom, 1993) as well as strategies in problem solving (Schultz \& Searleman, 1998).

Extraversion is also enhanced by the perception of a situation as high on cognitive load. It is related to social support seeking, which is a coping strategy to stressors and can thus explain this finding (Amirkhan, Risinger, \& Swickert, 1995)

The fourth model differently affected is resilience in combination with monotony. There is no fixed level-1 effect of the perception of a situation as monotone on resilience.

This effect of the perception of situations as high or low on strain and vigor (or the respective dimensions) may be of great importance not only for the study of personality in situations yet also for personality assessment in an occupational setting. Some evidence was 
presented that creating a work-related frame of reference for items of personality measures did increase their predictive validity (Hunthausen, Truxillo, Bauer, \& Hammer, 2003; Reddock, Biderman, \& Nguyen, 2011; Robie \& Schmit, 2000; Schmit, Ryan, Stierwalt, \& Powell, 1995). Even though only Schmit and colleagues (1995) assume a mechanism, namely realistic impression management, the situation perception could also serve as an explanation for this higher validity. An assessment situation that is closer to the actual situation on the job will lead to a more accurate display of personality traits in a way they are relevant for the actual job. The situation perception in the light of frame of reference theories with respect to the predictive validity of personality assessments might thus deserve further examination in future research.

Lewin's Equation could thus be extended by a person-specific variable that weights the effect of the situation and the personality. It would lead to a more precise prediction of behavior for some persons on the one hand and could, on the other hand, identify those persons whose behavior is less predictable by the personality only. 


\section{Limitations}

\section{Methodological Limitations}

The variables included in the models consisted partially of the same items. The same items that made up part of the level-2 predictor, $B 5_{j}$, measured the level-1 criterion hypothetical behavior, $P i S_{\mathrm{ij}}$. The same was true for the level-1 predictor situation perception, $S i P_{i j}$, and the level-2 predictor general situation perception, $S 5_{j}$. Separating these variables properly, for example by replacing the level-2 measures with results from different questionnaires or observations, could lead to more precise estimations of parameters. The highest correlation was found between mental and physical load measured in combination with extraversion (level-1) and the level-2 predictor mental and physical load, $\mathrm{r}_{\text {MPLiExtraversion, MPL }}=.50(p<.001$, two-tailed $)$. All other correlations between variables within one model that included the same items were lower.

The level-1 fixed effects of situations perception on hypothetical behavior were always significant. Since the items were measured within the same vignette, one might assign this effect to the vignette instead of the true effect of the perception on the behavior. This may be true for some items, but it is unlikely that this method effect is responsible for the consistent effect that presented itself with respect to the situation perception dimensions that are subsumed under the factors strain and vigor. Whereas the level-1 effect was negative for most of the strain-dimensions, it was mostly positive for the vigor-dimensions. A method effect should be distributed more randomly across these dimensions. Applying a latent model and applying the B5PS more than once could approach this problem. This might allow estimating the particular effect of one vignette on all participants, which could then be a fixed method effect for this vignette. Besides, a latent approach could also reduce the measurement error within the model, a general advantage of latent models over the multilevel models (Duncan \& Duncan, 2004).

\section{Other Limitations}

Baumeister and colleagues (2007) criticized psychological studies for testing behavior when actually self-reports are examined. This study is no exception and only hypothetical behavior is tested. Yet it is, in contrast to other questionnaire-based studies, very concrete hypothetical behavior in one particular situation and nevertheless a very good starting point for the examination of cross-situational perceiver effects on this behavior. Furthermore, this design allows easily replacing some variables by behavioral or psychophysical data, such as 
the already discussed level-2 predictor for the random slopes. An extension of this study could for example include an additional measure based on observations or friend reports on subjects and include it in the overall model.

The situations studied were located in an organizational setting. It is possible that for other settings different results emerge. This needs to be considered when generalizing the current findings. The results are therefore most valid when interpreted in an organizational environment.

Some findings are related to the strain and vigor factors reported by Ziegler (2014). The author himself points out that interpretation of these factors is not valid unless they could be replicated. It may be possible that the findings with respect to those two factors are completely sample-specific. Replicating this study as well as validating the findings in relation to these two super-factors could therefore be highly rewarding. 


\section{Conclusion}

This study has shown that the equation proposed by Lewin in 1936 could be investigated using the perception of situations instead of the environment as a valid predictor of behavior, after controlling for the influence of the individual's personality. The results seem to open a promising path for further investigation of the person as well as the situation. Claims made by Hogan (2009) and others about a lack of a situational taxonomy (e. g. Edwards \& Templeton, 2005; Saucier et al., 2007; Sherman et al., 2010) can finally be invalidated and the perception of a situation might take over the role as an effective classification system, even though the number of situation dimensions is still to be debated (Rauthmann et al., 2014). Furthermore, the effect of the current situation as perceived by the individual warrants exhaustive investigation in the future. This study generates hypotheses that could be assessed in different settings using different measures and even clinical samples.

It may furthermore serve as a starting point to increase the persistently mediocre predictive validities of some of the Big Five personality dimensions for career success and other relevant outcomes. By taking into account the specific effect the situation perception has for each person and each personality dimension, one may even reduce the reported variability of predictive validities for some personality dimension (Barrick et al., 2001; Barrick \& Mount, 1991).

Even though a large number of questions are still unanswered or were just triggered by this study, it still offers a sound starting point for the examination of the person in different environments. The design also generates lot of further research questions related to the person-situation debate. With the concept of situation perception the debate itself will hopefully move on to a new chapter.

Lewin's Equation has thus proven to be still a good theoretical framework and may even continue to be a guideline for the description and examination of human behavior. 


\section{References}

Allport, G. W., \& Odbert, H. S. (1936). Trait-names: A psycho-lexical study. Psychological Monographs, 47(1), i-171.

Amirkhan, J. H., Risinger, R. T., \& Swickert, R. J. (1995). Extraversion: A "hidden" personality factor in coping? Journal of Personality, 63(2), 189-212. doi:10.1111/j.1467-6494.1995.tb00807.x

Asendorpf, J. (2009). Personality: Traits and situations. In G. Matthews \& P. J. Corr (Eds.), The Cambridge Handbook of Personality Psychology (pp. 43-53). New York, NY, US: Cambridge University Press.

Barrick, M., \& Mount, M. (1991). The Big Five personality dimensions and job performance: A meta-analysis. Personnel Psychology, 44(1), 1-26. doi:10.1111/j.17446570.1991.tb00688.x

Barrick, M., Mount, M., \& Judge, T. A. (2001). Personality and performance at the beginning of the new millennium: What do we know and where do we go next? International Journal of Selection and Assessment, 9, 9-30. doi:10.1111/1468-2389.00160

Bates, D., Maechler, M., Bolker, B., \& Walker, S. (2014). lme4: Linear mixed-effects models using Eigen and S4. http://cran.r-project.org/package=lme4.

Baumeister, R. F., Vohs, K. D., \& Funder, D. C. (2007). Psychology as the science of selfreports and finger movements: Whatever happened to actual behavior? Perspectives on Psychological Science, 2(4), 396-403. doi:10.1111/j.1745-6916.2007.00051.x

Bem, D., \& Allen, A. (1974). On predicting some of the people some of the time. Psychological Review, 81(6), 506-520.

Bliese, P. (2002). Multilevel random coefficient modeling in organizational research: Examples using SAS and S-PLUS. In F. Drasgow \& N. Schmitt (Eds.), Measuring and analyzing behavior in organizations: Advances in measurement and data analysis. (pp. 401-445). San Francisco, CA, US: Jossey-Bass.

Connor-Smith, J. K., \& Flachsbart, C. (2007). Relations between personality and coping: a meta-analysis. Journal of Personality and Social Psychology, 93(6), 1080-107. doi:10.1037/0022-3514.93.6.1080

Cooper, W. H., \& Withey, M. J. (2009). The strong situation hypothesis. Personality and Social Psychology Review, 13(1), 62-72. doi:10.1177/1088868308329378

Craske, M. G., Rauch, S. L., Ursano, R., Prenoveau, J., Pine, D. S., \& Zinbarg, R. E. (2009). What is an anxiety disorder? Depression and Anxiety, 26(12), 1066-85. doi: 10.1002/da.20633

Deary, I. (2009). The trait approach to personality. In G. Matthews \& P. J. Corr (Eds.), The Cambridge handbook of personality psychology. Cambridge: Cambridge University Press.

Deinzer, R., Steyer, R., Eid, M., Notz, P., Schwenkmezger, P., Ostendorf, F., \& Neubauer, A. (1995). Situational effects in trait assessment: The FPI, NEOFFI, and EPI questionnaires. European Journal of Personality, 9, 1-23. doi:10.1002/per.2410090102

DeYoung, C. G. (2006). Higher-order factors of the Big Five in a multi-informant sample. Journal of Personality and Social Psychology, 91(6), 1138-51. doi:10.1037/00223514.91.6.1138

Digman, J. M. (1990). Personality structure: Emergence of the five-factor model. Annual Review of Psychology, 41(1), 417-440. doi:10.1146/annurev.ps.41.020190.002221 
Dumenci, L. (2000). Multitrait-multimethod analysis. In H. E. A. Tinsley \& S. D. Brown (Eds.), Handbook of applied multivariate statistics and mathematical modeling (pp. 583-611). San Diego, CA, US: Academic Press.

Duncan, T., \& Duncan, S. (2004). An introduction to latent growth curve modeling. Behavior Therapy, 35, 333-363.

Edwards, J., \& Templeton, A. (2005). The structure of perceived qualities of situations. European Journal of Social Psycholgy, 723(December 2004), 705-723.

Enders, C. K., \& Tofighi, D. (2007). Centering predictor variables in cross-sectional multilevel models: A new look at an old issue. Psychological Methods, 12(2), 121-38. doi:10.1037/1082-989X.12.2.121

Endler, N. S., \& Magnusson, D. (1976). Toward an interactional psychology of personality. Psychological Bulletin, 83(5), 956-74.

Epstein, S. (1979). The stability of behavior: On predicting most of the people much of the time. Journal of Personality and Social Psychology, 37(7), 1097-1126.

Epstein, S. (1983). The stability of confusion: A reply to Mischel and Peake. Journal of Personality and Social Psychology, 44(1), 107-112. doi:10.1037/0022-3514.44.1.107

Fleeson, W. (2004). Moving personality beyond the person-situation debate. The challenge and the opportunity of within-person variability. Current Directions in Psychological Science, 13(2), 83-87. doi:10.1111/j.0963-7214.2004.00280.x

Fleeson, W., \& Noftle, E. E. (2009). In favor of the synthetic resolution to the personsituation debate. Journal of Research in Personality, 43(2), 150-154. doi:10.1016/j.jrp.2009.02.008

Funder, D. C. (2006). Towards a resolution of the personality triad: Persons, situations, and behaviors. Journal of Research in Personality, 40(1), 21-34. doi:10.1016/j.jrp.2005.08.003

Funder, D. C. (2009). Persons, behaviors and situations: An agenda for personality psychology in the postwar era. Journal of Research in Personality, 43(2), 120-126. doi:10.1016/j.jrp.2008.12.041

Furr, R. M., \& Funder, D. C. (2004). Situational similarity and behavioral consistency: Subjective, objective, variable-centered, and person-centered approaches. Journal of Research in Personality, 38(5), 421-447. doi:10.1016/j.jrp.2003.10.001

Hogan, R. (2009). Much ado about nothing: The person-situation debate. Journal of Research in Personality, 43(2), 249. doi:10.1016/j.jrp.2009.01.022

Hox, J. (2010). Multilevel analysis: Techniques and applications (2nd ed.). New York, NY, US: Routledge.

Hunthausen, J. M., Truxillo, D. M., Bauer, T. N., \& Hammer, L. B. (2003). A field study of frame-of-reference effects on personality test validity. Journal of Applied Psychology, 88(3), 545-551. doi:10.1037/0021-9010.88.3.545

IPIP. (2015). International Personality Item Pool: A scientific collaboratory for the development of advanced measures of personality traits and other individual differences. Retrieved February 17, 2015, from http://ipip.ori.org/

John, O., \& Srivastava, S. (1999). The Big Five trait taxonomy: History, measurement, and theoretical perspectives. In The Big Five Trait taxonomy: History, measurement, and theoretical perspectives (pp. 102-138). 
Johnson, J. A. (1999). Persons in situations: Distinguishing new wine from old wine in new bottles. European Journal of Personality, 13(5), 443-453. doi:10.1002/(SICI)10990984(199909/10)13:5<443::AID-PER358>3.0.CO;2-9

Judge, T. A., Heller, D., \& Mount, M. K. (2002). Five-factor model of personality and job satisfaction: A meta-analysis. Journal of Applied Psychology, 87(3), 530-541. doi:10.1037//0021-9010.87.3.530

Kenrick, D., \& Funder, D. (1988). Profiting from controversy. American Psychologist, 43(1), 23-34.

LaHuis, D. M., \& Ferguson, M. W. (2007). The accuracy of significance tests for slope variance components in multilevel random coefficient models. Organizational Research Methods, 12(3), 418-435. doi:10.1177/1094428107308984

Lewin, K. (1936). Principles of topological psychology. New York-London. New York: McGraw Hill.

Lucas, R. E., \& Donnellan, M. B. (2011). Personality development across the life span: longitudinal analyses with a national sample from Germany. Journal of Personality and Social Psychology, 101(4), 847-61. doi:10.1037/a0024298

Lydiard, R. B. (2003). The role of GABA in anxiety disorders. The Journal of Clinical Psychiatry, 64 Suppl 3, 21-7.

Maas, C. J. M., \& Hox, J. J. (2005). Sufficient sample sizes for multilevel modeling. Methodology, 1, 86-92. doi:10.1027/1614-2241.1.3.86

Magnusson, D. (1971). An analysis of situational dimensions. Perceptual and Motor Skills, 32(3), 851-867. doi:10.2466/pms.1971.32.3.851

Mischel, W. (1968). Personality and assessment. New York: Wiley.

Mischel, W. (1977). The interaction of person and situation. In D. Magnusson \& N. S. Endler (Eds.), Personality at the cross-roads: Current issues in interactional psychology (pp. 333-352). Hilsdale, NY: Lawrence Erlbaum.

Mischel, W. (2004). Toward an integrative science of the person. Annual Review of Psychology, 55, 1-22. doi:10.1146/annurev.psych.55.042902.130709

Mischel, W. (2009). From Personality and Assessment (1968) to Personality Science, 2009. Journal of Research in Personality, 43(2), 282-290. doi:10.1016/j.jrp.2008.12.037

Mischel, W., \& Peake, P. K. (1982). Beyond déjà vu in the search for cross-situational consistency. Psychological Review, 89(6), 730-755.

Mischel, W., \& Shoda, Y. (1995). A cognitive-affective system theory of personality: Reconceptualizing situations, dispositions, dynamics, and invariance in personality structure. Psychological Review, 102(2), 246-68.

Mischel, W., Shoda, Y., \& Mendoza-Denton, R. (2002). Situation-Behavior profiles as a locus of consistency in personality. Current Directions in Psychological Science, 11(2), 50-54. doi:10.1111/1467-8721.00166

Neuberg, S., \& Newsom, J. (1993). Personal need for structure: Individual differences in the desire for simpler structure. Journal of Personality and Social Psychology, 65(1), 113131.

Ones, D. S., Mount, M. K., Barrick, M. R., \& Hunter, J. E. (1994). Personality and job performance: A critique of the Tett, Jackson, and Rothstein (1991) meta-analysis. Personnel Psychology, 47, 147-156. doi:10.1111/j.1744-6570.1994.tb02414.x 
Orom, H., \& Cervone, D. (2009). Personality dynamics, meaning, and idiosyncrasy: Identifying cross-situational coherence by assessing personality architecture. Journal of Research in Personality, 43(2), 228-240. doi:10.1016/j.jrp.2009.01.015

Ozer, D. J., \& Benet-Martínez, V. (2006). Personality and the prediction of consequential outcomes. Annual Review of Psychology, 57, 401-421. doi:10.1146/annurev.psych.57.102904.190127

Pinheiro, J., \& Bates, D. (2000). Mixed-effects models in S and S-PLUS. New York, NY, US.

$\mathrm{R}$ Core Team. (2014). R: A language and environment for statistical computing. $R$ Foundation for Statistical Computing, Vienna, Austria. http://www.R-project.org/.

Rauthmann, J. (2011). You say the party is dull, I say it is lively: A componential approach to how situations are perceived to disentangle perceiver, situation, and perceiver $\mathrm{x}$ situation variance. Social Psychological and Personality Science, 3(5), 519-528. doi:10.1177/1948550611427609

Rauthmann, J., Gallardo-Pujol, D., Guillaume, E. M., Todd, E., Nave, C. S., Sherman, R. A., ... Funder, D. C. (2014). The situational eight DIAMONDS: A taxonomy of major dimensions of situation characteristics. Journal of Personality and Social Psychology, 107(4), 677-718. doi:10.1037/a0037250

Reddock, C. M., Biderman, M. D., \& Nguyen, N. T. (2011). The relationship of reliability and validity of personality tests to frame-of-reference instructions and within-person inconsistency. International Journal of Selection and Assessment, 19(2), 119-131. doi:10.1111/j.1468-2389.2011.00540.x

Reis, H. T. (2008). Reinvigorating the concept of situation in social psychology. Personality and Social Psychology Review, 12(4), 311-29. doi:10.1177/1088868308321721

Revelle, W. (2014). psych: Procedures for Psychological, Psychometric, and Personality Research. http://CRAN.R-project.org/package=psych Version $=1.4 .5$.

Roberts, B. W., \& DelVecchio, W. F. (2000). The rank-order consistency of personality traits from childhood to old age: a quantitative review of longitudinal studies. Psychological Bulletin, 126, 3-25. doi:10.1037/0033-2909.126.1.3

Robie, C., \& Schmit, M. (2000). Effects of item context specificity on the measurement equivalence of a personality inventory. Organizational Research Methods, 3(4), 348365.

Salgado, J. F. (1997). The Five Factor Model of personality and job performance in the European Community. The Journal of Applied Psychology, 82(1), 30-43.

Samuel, D. B., \& Widiger, T. A. (2011). Conscientiousness and obsessive-compulsive personality disorder. Personality Disorders, 2(3), 161-74. doi:10.1037/a0021216

Saucier, G., Bel-Bahar, T., \& Fernandez, C. (2007). What modifies the expression of personality tendencies? Defining basic domains of situation variables. Journal of Personality, 75(3), 479-503. doi:10.1111/j.1467-6494.2007.00446.x

Schmidt, F. L., \& Hunter, J. E. (1998). The validity and utility of selection methods in personnel psychology: Practical and theoretical implications of 85 years of research findings. Psychological Bulletin, 124(2), 262-274. doi:10.1037//0033-2909.124.2.262

Schmit, M. J., Ryan, A. M., Stierwalt, S. L., \& Powell, A. B. (1995). Frame-of-reference effects on personality scale scores and criterion-related validity. Journal of Applied Psychology, 80(5), 607-620. doi:10.1037//0021-9010.80.5.607

Schultz, P. W., \& Searleman, A. (1998). Personal need for structure, the Einstellung task, and the effects of stress. Personality and Individual Differences, 24(3), 305-310. doi:10.1016/S0191-8869(97)00179-7 
Sherman, R. A., Nave, C. S., \& Funder, D. C. (2010). Situational similarity and personality predict behavioral consistency. Journal of Personality and Social Psychology, 99(2), 330-43. doi:10.1037/a0019796

Shoda, Y., \& Mischel, W. (2000). Reconciling contextualism with the core assumptions of personality psychology. European Journal of Personality, 14, 407-428. doi:10.1002/1099-0984(200009/10)14:5<407::AID-PER391>3.0.CO;2-3

Shoda, Y., Mischel, W., \& Wright, J. C. (1994). Intraindividual stability in the organization and patterning of behavior: Incorporating psychological situations into the idiographic analysis of personality. Journal of Personality and Social Psychology, 67(4), 674-87.

Snijders, T., \& Bosker, R. (1999). Multilevel analysis: An introduction to basic and advanced multilevel modeling. Sage, London.

Tett, R. P., \& Burnett, D. D. (2003). A personality trait-based interactionist model of job performance. Journal of Applied Psychology, 88(3), 500-517. doi:10.1037/00219010.88.3.500

Tett, R. P., \& Guterman, H. A. (2000). Situation trait relevance, trait expression, and crosssituational consistency: Testing a principle of trait activation. Journal of Research in Personality, 34(4), 397-423. doi:10.1006/jrpe.2000.2292

Van Mechelen, I., \& De Raad, B. (1999). Editorial: personality and situations. European Journal of Personality, 13(5), 333-336. doi:10.1002/(SICI)10990984(199909/10)13:5<333::AID-PER364>3.0.CO;2-O

Viswesvaran, C., \& Ones, D. S. (2000). Measurement error in "Big Five Factors" personality assessment: reliability generalization across studies and measures. Educational and Psychological Measurement, 60(2), 224-235. doi:10.1177/00131640021970475

Vollrath, M. (2001). Personality and stress. Scandinavian Journal of Psychology, (42), 335347.

Wagerman, S., \& Funder, D. (2009). Personality psychology of situations. In P. J. Corr \& G. Matthews (Eds.), The Cambridge handbook of personality psychology (pp. 27-42). New York, NY, US: Cambridge University Press.

Wald, A. (1943). Tests of statistical hypotheses concerning several parameters when the number of observations is large. Transactions of the American Mathematical Society, $54(3), 426-483$.

Yang, Y., Read, S. J., \& Miller, L. C. (2006). A taxonomy of situations from Chinese idioms. Journal of Research in Personality, 40(5), 750-778. doi:10.1016/j.jrp.2005.09.007

Ziegler, M. (2014). Big Five Inventar zur Persönlichkeit in beruflichen Situationen. Mödling, Austria: SCHUHFRIED GmbH. 


\section{Eidesstattliche Erklärung}

Ich erkläre hiermit eidesstattlich, die vorliegende Masterarbeit selbstständig und ohne fremde Hilfe verfasst zu haben. Andere als die angegebenen Quellen und Hilfsmittel habe ich nicht benutzt und die den benutzten Quellen wörtlich oder inhaltlich entnommenen Stellen wurden als solche gekennzeichnet. Die Arbeit wurde bisher in gleicher oder ähnlicher Form keiner anderen Prüfungskommission vorgelegt und auch nicht veröffentlicht.

Berlin, 27.02.2015 